\title{
REVIVENDO A CULPA E O DESAMPARO: RESENHA DE UMA JORNADA COMO TANTAS, DE FRANCISCO J. C. DANTAS
}

RELIVING THE GUILT AND THE DERELICTION: REVIEW OF FRANCISCO J. C. DANTAS' UMA JORNADA COMO TANTAS

DANTAS, FRANCISCO. J. C. UMA JORNADA COMO TANTAS. RIO DE JANEIRO: ALFAGUARA, 2019.

Pedro Barbosa Rudge Furtado*

Luiz Costa Lima (2006, p.353-354) diferencia o modo de trabalho do que ele chama "autobiografia pura" e a escrita de memórias. De acordo com o intelectual, a modulação autobiográfica não funde passado e presente no discurso, usando o passado apenas como fonte de escrita sobre o presente, sendo o discurso uma maneira "como o a utor, contraria ndo a ordem verificável dos eventos, se vê (se fantasia) a si mesmo." Assim, não haveria a tensa reavaliação dos fatos pelo narrador sobre o outrora. As memórias, um pouco distintamente, evidenciam a miúde a "face interna" do sujeito em sua ligação a rraigada com o passado, criando uma dupla inscrição ótica: muitas vezes, a voz narrativa tenta mimetizar as sensações dos acontecimentos de então, mesmo que elas estejam em constante
* pedro.sonata@gmail.com

Doutorando pelo Programa de Pós-graduação em Estudos Literários da Universidade Estadual Paulista "Júlio de Mesquita Filho"

(Araraquara-SP).

a tualização conflitiva pelo contador da história no presente da enunciação.

Na ficção, emular o memorialismo é um dos tantos recursos que podem ser usados pelos romancistas, o que é realizado com maestria na nova narrativa de Francisco J. C. Dantas, chamada Uma jornada como tantas. Neste livro, as recordações são tão invasivas na narração de Valdomiro - narrador-personagem - que os tempos verbais do passado são continuamente solapados pelos do presente, conferindo um efeito de permanência psíquica da dor de outrora. A narrativa do sofrimento através da memória engendra a construção de uma certa poética da memória, pautada sobretudo na sua labilidade, como é visto logo nas primeiras linhas da prosa: "A lembrança do tempo carregado de nuvens cinzentas, que 
embaciavam e contraíam o horizonte, reatualiza e infla ma as minhas recordações" (DANTAS, 2019, p. 7).

Inevitável nos recordarmos do símbolo das nuvens - essa representação das memórias retalhadas - em Infância, de Graciliano Ramos; lá, mais fortemente do que cá, a revisitação do escritor alagoano elabora uma esmagadora carga de impressões que, de modo fragmentário, constroem um discurso "meio sonho, meio vigília, meio ressoo íntimo, meio império da voz alheia” (BOSI, 2013, p. 90) figurado pelo signo das nuvens densas que atrapalham a visão clara sofre os fatos.

No romance de Dantas, o tom fracionário da obra é menos intenso, pois Valdomiro, o protagonista, recorda a sua adolescência - aos 15 anos - não o passado extrema mente longínquo e quase inacessível de uma criança de 2, 3 anos como nas memórias do compositor de Angústia; o símbolo das nuvens, ainda, no romance de 2019, enceta o prenúncio da morte, como veremos. Vale ressaltar que, assim como no livro de Graciliano Ramos, o estabelecimento da metalinguagem rememorativa, na prosa de Dantas, não concebe um discurso ensaístico estéril, fora de prumo.

Pelo contrário, a poética reforça e justifica as falhas mnemônicas do órfão Valdomiro muito devido à angustiosa matéria do seu relato: a travessia da madrinha moribunda num carro-de-bois em direção a uma cidade que consiga acolher a mulher sofrendo um longo, laborioso e cruel trabalho de parto. Esse desloca mento é o impulso vital da narrativa, como é atestado no primeiro capítulo; no entanto, como em uma contação de histórias, o narrador deseja fixar os traços dos seus entes a partir de sua perspectiva absorvida por uma comovente rede de afetos.

O olhar em direção ao outro da instância narrativa concebe a formação de biografias de Teodoro, da Madrinha e, especialmente, da união dos dois celebrada com o concebimento de três filhos. Do capítulo dois a té o final do quatro, Valdomiro concentra-se quase tão somente na história do casal, preterindo a sua própria; ocasionalmente refere-se ao eu, o que aparenta ser um artifício testemunhal de marcação temporal a fim de sedimentar o "quando" e o "como" dos episódios contados.

No quinto capítulo do romance, o narrador volta-se para o pretérito motivador da narrativa: o quarto parto da Madrinha. Todavia, do quinto ao começo do oitavo capítulos o relato escora-se na tentativa de Sinha Amália - a parteira dos outros filhos dos cônjuges - conduzir o nascimento da criança. Nesse instante desponta em Valdomiro o apego a uma culpa indelével carregada até a sua meia-idade. Ela está ligada à sensação de que ele, incumbido de buscar Sinha Amália em outra vila, poderia tê-la transportado 
1. Há um trecho especial em que o narrador declara, ainda que náo abertamente, história em que ele na protagonista em náo e e trech em que rata após aques incidentes, apos aqueles incidentes, elo diferena a narraça, muito compõe, com compóe, com detahes, a "Pra biográrica dos ontes: Pra encurtar a historia, esse primo de Madrinha, que servia aos Correios, arranjou colocação num" (DANTAS, 2019, p. 177). mais rapida mente. Não o fez, no entanto, avalia ndo que o parto seria tranquilo como os outros. Acercando-se das adversidades intensas do novo nascimento, a partir da revisitação conflitiva da memória, ele pensa:

Será que eu demorara além da conta? Começavam aqui as espinhadelas na minha consciência. Se tivesse andando mais ligeiro, talvez a Madrinha já houvesse despachado a contento. Sim ou não? A verdade é que fiquei com aquele peso alojado na cabeça (DANTAS, 2019, p. 62, grifo nosso).

A questão grifada ecoa em toda a narrativa, estando a tada aos movimentos do processo narrativo travado pelo protagonista; isto é, ele desnuda a sua perturbação de acordo com o andamento dos episódios lembrados; mais do que isso, nos momentos ilhados em que a perspectiva da história recai sobre o eu, ${ }^{1}$ constata-se que, talvez, a emoção-chave em jogo no relato seja a do desamparo.

Acerca do desamparo, Freud (1986, p. 307) afirma que esse é primeiro afeto a a tingir, inicialmente, "todos os seres humanos", sendo "a fonte primordial de todos os motivos morais". Desde o momento do nascimento, qua ndo o bebê é retirado da proteção materna, o homem sente-se desamparado. Durante a vida, o sujeito enfrenta diversas vezes esse estado, de modo mais ou menos prolongado.
Na história de Valdomiro, o abrigo do órfão é recuperado quando ele é adotado pela Madrinha e Teodoro. Nesse caso, a morte da figura materna - simbolicamente a segunda institui a exacerbação do abandono, sobretudo quando se trata do ente mais querido. $\mathrm{O}$ narrador-personagem não esconde a adoração poderosa - e sobera na - conferida a ela. Ademais, o casal o acomoda em sua casa - tipo de espaço que, segundo Bachelard (1993, p. 200), é o canto íntimo do indivíduo no mundo -, dando-lhe proteção e espaço para o enraizamento do narrador; anos após o falecimento de Madrinha, no entanto, Valdomiro retira-se da miúda cidade nordestina, afastando-se espacialmente dos afetos fantasmáticos.

$\mathrm{Na}$ esteira desse pensa mento, responsabilizar-se pelo falecimento da mulher corresponde à expansão do sentimento melancólico do sujeito preso fatalmente ao passado doloroso. A mela ncolia, a propósito, irradia a culpa. Os sujeitos saturninos "parecem sentir necessidade de alardear suas baixezas e sua indignidade" (KEHL, 2013, s. p.). Valdomiro, mesmo em uma procura inconsciente, empenha-se em compartilhar a culpa com o outro, principalmente com Teodoro - minimizando a sua própria responsabilidade e desviando-se parcialmente da melancolia - que decidiu não encarar a via crucis faulkeriana, confiando ao narrador essa tarefa. Valdomiro, então, confessa: 
Embora siga aqui a mando de Teodoro, justo para olhar pela Madrinha, a bem da verdade, encaro esta viagem com desgosto. Aborrecido. Não sou eu quem devia andar aqui. Nem mesmo cheguei a me comprometer claramente. Já tivera indícios de que não tenho estômago para acompanhar tanta sofrência escanchada numa criatura inocente (DANTAS, 2019, p. 104).

O último período, em que ele escancara a fraqueza de Teodoro e a dele, alimenta a partilha da culpa: "Mas sei que só vou aqui porque não tive coragem para desapontar Teodoro. E me dói a sua fraqueza. E a minha ta mbém. [...] Tenho ou não tenho alguma culpa nessa história?" (DANTAS, 2019, p. 105). Em consequência do andamento lento da viagem, guiada em espaços tortuosos pelo sisudo, intransigente e habilidoso Zé Carreiro, agravam-se os problemas da enferma; homologamente, o narrador faz uso mais reiterado de palavras inseridas no campo semântico da tristeza, como "desencanto", "abandono" e "mal-estar" (DANTAS, 2019, p. 122-123).

Essa reunião de semas, provocada pela morrediça mulher, pinta a jornada em tons de pavorosa angústia, de medo do porvir ao mesmo tempo em que ele já é conhecido. O narrador confidencia que aquela é "uma viagem sem sentido” (DANTAS, 2019, p. 144), absurda no desfecho claramente trágico. As próprias nuvens, como dados da paisagem antropomorficamente desolada e profetizadora, os "acompanhava m enlutadas" (DANTAS, 2019, p. 153).

Há alguns indícios de possível sucesso nas tentativas de salvar o bebê e a mãe; eles são, porém, efêmeros, esbarrando em mandonismos políticos. A propósito, a narrativa suscita graves tensões socioculturais, sobretudo por meio da voz narrativa que enxerga o espaço passado como uma “ordem bárbara” (DANTAS, 2019, p. 162) ao a nalisar os costumes da vila em que morava. A mirada do narrador então, é a do civilizado esclarecido, daquele que vive, no presente da enunciação, no Sudeste, centro econômico do país. Não cabe, neste breve texto, desenvolver essa outra camada conflitiva do romance.

Ocupando-nos mais da carga ontológica do relato, a presentificação do outrora funesto figura uma tentativa de cura do sofrimento pela escrita e/ou atesta o não desapego lamentoso de Valdomiro por tal recorte trágico? As suas confissões podem nos remeter a uma tentativa de regeneração da consciência através da tortuosa culpa. Todavia, a mesma honestidade discursiva, característica do melancólico, o faz declarar, no final do romance, que ele está dentro da cena da morte e "mais uma vez nada faço" (DANTAS, 2019, p. 238). 
A culpa pela inércia de antes, portanto, continua assaltando-o, não apaziguando o passado do desamparado. Perseguindo esse pensamento, a recriação da figura materna soa como a reprodução de um terceiro desabrigo: o primeiro ao ser abandonado pela mãe biológica, o segundo no ato de falecimento da figura materna que o criou e o terceiro na elaboração de uma prosa memorialista-melancólica, representante da ligação vigorosa com o outro ausente.

\section{REFERENCIAS}

BACHELARD, Gaston. A poética do espaço. Tradução de Antônio da Costa Leal e Lídia do Valle Santos Leal. São Paulo: Martins Fontes, 1993.

BOSI, Alfredo. Passagens de Infância de Graciliano Ramos. In: . Entre a literatura e a história. São Paulo: Editora 34 2013. p. 87-111.

DANTAS, Francisco. J. C. Uma jornada como tantas. Rio de Janeiro: Alfaguara, 2019.

FREUD, Sigmund. Projeto para uma psicologia científica [1895]. In: Edição Standard Brasileira das Obras Completas de Sigmund Freud. Rio de Janeiro: Imago, vol. I, 1986. p. 303-314.
KEHL, Maria Rita. Melancolia e criação. In: FREUD, Sigmund. Luto e melancolia. Tradução de Marilene Carone. São Paulo: Cosac Nayfi, 2013. Formato e-book.

LIMA, Luiz Costa. História. Ficção. Literatura. São Paulo: Companhia das Letras, 2006.

Recebido em: 28-02-2020. Aceito em: 30-04-2020. 